\title{
CONSUMER PERCEPTION AS A TOOL FOR THE STRATEGIC DEVELOPMENT OF ECOLOGICALLY- ORIENTED PRODUCTS
}

\section{Thamyres Oliveira Clementino, (UFPE); Amilton José Vieira de Arruda, PhD.}

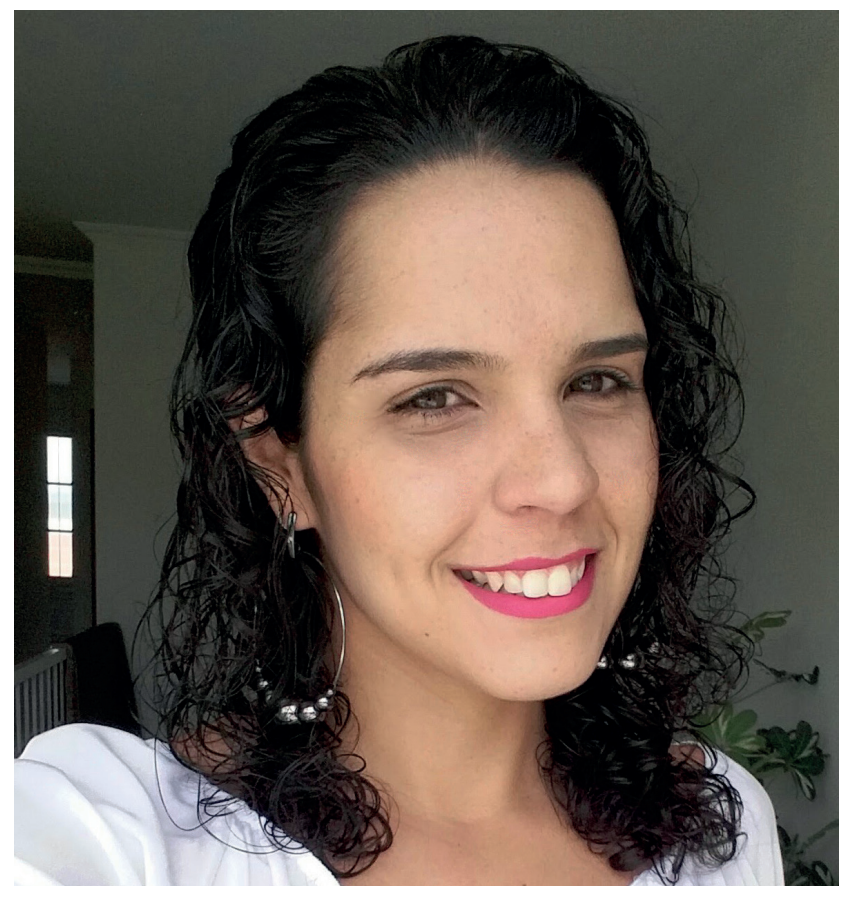

Thamyres Oliveira Clementino

Concern about the environment has been changing the way how designers conceive products. This factor is perceived, since the twentieth century was marked by the development of methods and strategies focused on reducing the environmental damage caused by artifacts. Minimization of resources, the choice of low environmental impact processes, the optimization of life, the extension of the lifetime of the materials and the ease of disassembly were adopted. (KAZAZIAN, 2005, p.51). All these changes in the design of the artifacts led to the emergence of a new category of products committed to the environmental issue, ecologically oriented products.

In this scenario, design has focused almost exclusively on the adoption of the aforementioned practices, but little attempt has been made to demonstrate them strategically for the consumer. According to Manzini (2008), design skills should provide coherence to products and services, creating sustainable solutions, but in addition, they must communicate visions and systems in an appropriate way so that the recognition and evaluation of ecologically more coherent products be favored. Krucken and Trusen (2009), discuss the use of communication strategies as a way of exposing the qualities of the product or service and their contribution to sustainability, since the value attributed to an artifact depends on perceived quality. They argue that communication strategy is an effective way to expose information about product sustainability and thus to make consumers aware of the values involved in production and consumption.

For Vezzoli (2010), aesthetics have a fundamental role in this context, because "an environmentally sustainable innovation, without being perceived as an improvement (compared to obsolete solutions), is not enough". In this perspective, the importance of the appearance of the ecologically oriented products can be worked out in order to facilitate the recognition by the consumer, using visual means of communication that favors their perception more effectively.

The designer can seek strategies that help the consumer's perception about the orientation of the product through strategies of association between the theme 'environmental sustainability' and the repertoire of the individuals. This is possible since according to Cardoso (2014, p.111-117) the design can add value to the artifacts through abstract concepts.

This research seeks to understand, through consumer perception, which strategies can be used for the aesthetic development of sustainable products, favoring their recognition as a less harmful category to the environment. In this perspective, the consumer is the starting point to devise strategies that provide the association between structural, graphic and shape attributes and the values involved in the perception of sustainability, which in turn, allow better results in the design practice of ecologically oriented products. 